\title{
Música híbrida na Amazônia: peculiaridades do punk rock em Belém do Pará
}

\author{
Keila Michelle Silva Monteiro \\ Universidade Federal do Pará | Orcid: 0000-0002-2502-5488
}

\section{Resumo}

Este artigo trata de uma pesquisa em andamento na qual se busca perceber a hibridação como algo presente nas composiçóes de bandas de punk rock na região amazônica, visto que este subgênero do rock se faz presente desde o início dos anos 80 em Belém do Pará. As bandas punks compóem um universo cultural híbrido propício para que se busque suas perspectivas epistêmicas, seu diálogo com outras culturas numa visão inter e transdisciplinar. Investigar os diálogos possíveis entre os saberes da região e de localidades externas, inclusive dos países que geraram esse estilo musical, que permeiam a cultura das bandas punks em Belém de modo a buscar suas interfaces epistêmicas é um incentivo à pesquisa de música urbana na região, sendo que cada gênero ou subgênero musical guarda suas particularidades da regiấo e de outras localidades.

Palavras-chave: Amazonia, Belém do Pará, punk rock, música híbrida.

\section{Hybrid music in the Amazon: peculiarities of punk rock in Belém do Pará}

\section{Abstract}

This article is about an ongoing research in which it seeks to perceive hybridization as something present in the compositions of punk rock bands in the Amazon region, since this subgenre of rock has been present since the early 1980s in Belém do Pará. punk bands make up a hybrid cultural universe conducive to looking for their epistemic perspectives, their dialogue with other cultures in an inter and transdisciplinary view. Investigating the possible dialogues between the knowledge of the region and external locations, including the countries that generated this musical style, which permeate the culture of punk bands in Belém in order to seek their epistemic interfaces is an incentive to research urban music in the region, each musical genre or subgenre keeps its particularities in the region and other locations.

Keywords: Amazon, Belém do Pará, punk rock, hybrid music.

\section{Música híbrida en la Amazonia: peculiaridades del punk rock en Belém do Pará}

\section{Resumo}

Este artículo trata sobre una investigación en curso en la que busca percibir la hibridación como algo presente en las composiciones de las bandas de punk rock en la región amazónica, ya que este subgénero del rock ha estado presente desde principios de la década de 1980 en Belém do Pará. Las bandas de punk conforman un universo cultural híbrido propicio para buscar sus perspectivas epistémicas, su diálogo con otras culturas en una visión interdisciplinaria y transdisciplinaria. Investigar los posibles diálogos entre el conocimiento de la región y las ubicaciones externas, incluidos los países que generaron este estilo musical, que impregna la cultura de las bandas de punk en Belém para buscar sus interfaces epistémicas, es un incentivo para investigar la música urbana en la región. Cada género musical o subgénero mantiene sus particularidades en la región y otros lugares.

Palabras clave: Amazonia, Belém do Pará, punk rock, música híbrida. 


\section{Introduçáo}

Na música urbana produzida na Amazônia há grupos formados por músicos que adotaram o rock como seu estilo não apenas musical, mas um estilo de vida. Optei por delimitar minha pesquisa a grupos que praticavam o chamado punk rock, considerado subgênero do rock, em espaços tidos como cena underground ${ }^{1}$ nos anos 80 e 90 , em Belém do Pará, sendo que alguns desses grupos afirmam que suas atitudes de manusear instrumentos musicais eram consequências de sua atuação imbuída de protestos sociopolíticos, desconsiderando o rótulo 'punk rock', definindo este produto com antimúsica.

Este trabalho é um registro etnográfico desses grupos de punks, que frequentavam a regiáo metropolitana de Belém nesse determinado período, praticando (anti)música na cena underground, visto que não há bibliografia referente a este tipo de produto musical em Belém. Pretendo identificar, em diálogo com distintas áreas de conhecimento (VELHO, 2011), esses "circuitos de jovens" (MAGNANI, 2007), seus comportamentos, relaçóes de trocas e conflitos, sua performatividade (Féral, 2009), sua inserção na paisagem urbana de uma capital amazônida, num contexto pós-ditadura, com muitos problemas sociais, econômicos e políticos, propício a intervenções, sejam elas estéticas, artísticas ou por ação direta; pois conforme Caiafa (1985) "É o punk que resgata a força política do rock ao fazer dele (imediatamente, diretamente) um instrumento de intervenção - na forma da música, nas letras, na atitude" (p. 11).

Abramo (1994) retrata um pouco essa performatividade em consonância com Yonnet (1985) ao afirmarem que os punks são grupos que utilizam miséria e aspereza na sua criação, dissonância e estranheza para causar choque rompendo com parâmetros de beleza e virtuosismo, valorizando o caos, a cacofonia de referências e signos para produzir confusão, a intenção de provocar, de produzir interferências perturbadoras da ordem.

Os dados coletados para este trabalho provém de conversas informais e entrevistas semiestruturadas com os punks que (per)formaram suas bandas na época e de áudios de gravaçóes do seu produto (anti)musical. Procuro pontuar, ainda, algumas peculiaridades acerca da adaptação desse gênero estrangeiro à região amazônica, como por exemplo, o tipo de vestimenta mais adequado ao clima quente e úmido da capital paraense, as letras cantadas em português, condizentes com a realidade local, dentre outras coisas, sem, no entanto, haver perda da essência punk.

De acordo com as ideias de Gerard Béhague (1992), John Blacking (1990) e Alan Merrian (1964), que consideram fatores socioeconômicos no processo de criação musical, busco traçar este perfil das bandas, de seus integrantes. Num primeiro momento, relato as origens do punk sob o aspecto musical que ficou definido como punk rock, num segundo momento, a assimilação do gênero no Brasil e por fim, a cena na cidade de Belém, com um tópico específico para os grupos de punks que gravaram a coletânea Gritos de Agonia e Desespero, um dos registros mais importantes em áudio da cena punk no Pará na época de sua efervescência; sem haver, no entanto, pretensão de esgotar o tema.

1 Termo que define o espaço não cooptado pela grande mídia. A produçáo artística que circula nesse espaço é comprometida com a arte e náo com o comércio. 


\section{Origens do Punk Rock}

$\mathbf{E}_{\text {ntre grupos que adotam o rock como seu estilo musical, encontra-se um }}$ segmento específico denominado punk rock, o qual foi absorvido por músicos na capital paraense no início dos anos 80 . Porém, o movimento punk em si iniciou não apenas com a música, pois esta se tornava consequência de questionamentos sociais, políticos, econômicos e culturais emergentes tanto em seus locais de origem quanto naqueles por onde se expandiu.

Para compreender seu aparecimento como (sub)gênero musical, devemos considerar um pequeno recorte na história da música ocidental do século passado.

Durante o final dos anos 60 e início dos anos 70, o rock sofreu alguns exageros em suas formas em comparação ao formato musical inicial, procurou atingir um extremo que o levasse a uma superação, a certa erudição, surgindo assim o rock progressivo ${ }^{2}$. Em meados dos anos 70 surgiu a discoteca que nos remetia às origens do rock, descomprometida, sem mensagem social ou política, com música feita apenas para dançar. Mas o rock desta época já estava sendo feito para ser 'ouvido', ou seja, possuía letras mais reflexivas. Então, uma crítica à base ideológica do rock começou no início dessa década, em Nova York, com bandas como Lou Reed e Velvet Underground, continuou com David Bowie e assumiu um traço definitivo com o movimento punk, fenômeno que surgiu em países como Inglaterra, Estados Unidos e Austrália, historicamente entre 1974 e 1977, uma nova subcultura juvenil, de estética inusitada, estética essa que não permeava apenas sua aparência física, mas seu conteúdo musical, como uma variante do rock, como se observa no livro de Helena Abramo "Cenas Juvenis: punks e darks no espetáculo urbano":

São grupos fundados em atitudes como a rejeiçáo de aparatos grandiosos e de conhecimento acumulado, em troca da utilização da miséria e aspereza como elementos básicos de criação, o uso de dissonância e estranheza para causar choque, o rompimento com os parâmetros de beleza e virtuosismo, a valorização do caos, a cacofonia de referências e signos para produzir confusão, a intenção de provocar, de produzir interferências perturbadoras da ordem [...] (YONNET, 1985 apud ABRAMO, 1994, p. 42-44).

A música do chamado punk rock emergiu, portanto, rejeitando erudiçóes, virtuosismos, como reação ao rock progressivo, à discoteca, tendo o movimento punk como um conceito de contracultura. De acordo com Gabriel dos Santos (2013) o termo contracultura foi usado, em princípio, pela imprensa norte-americana, no início da década de 60, para identificar grupos de jovens que, tanto no seu exterior quanto na sua forma de pensar, diferiam das "normas" sociais e culturais vigentes.

Os maiores representantes do punk rock na Inglaterra eram os grupos The Damned, Sex Pistols, The Clash e outros que mantinham os ideais do punk, recusando-se, a princípio, a aceitar convites de grandes gravadoras, porque assim estariam se vendendo ao sistema que tanto combatiam. Nos EUA, o trabalho prosseguia com New York Dolls e Heartbreakers. Mas a morte do guitarrista Sid Vicious, da banda Sex Pistols coincidiu com o enquadramento das melhores bandas punks nos limites que as gravadoras impunham.

Após os anos 60, então, o rock ganhou um caráter mais político, tornando-se algo muito além de um simples gênero musical, configurando-se como uma forma de evidenciar a realidade, contribuindo com o desenvolvimento social, e isso se acentuou com o punk

$2 \quad$ Subgênero do rock que surgiu no fim da década de 1960, na Inglaterra, com influências da música erudita e do jazz fusion, em contraste com o rock norte-americano, historicamente influenciado pelo rhythm and blues e pela música country. Suas composiçôes são longas com harmonia e melodias complexas. 
rock. Percebe-se na sua origem o caráter social e político do movimento representado na sua música, visto que suas composiçôes tinham letras que criticavam negativamente o sistema em que viviam, com som agressivo, em que o vocalista canta de forma a dar gritos, acompanhado por guitarras com efeitos de distorção, dissonância e estranheza, como relatado pelo pesquisador Paul Yonnet apud Abramo.

Os grupos punks em si caracterizam sua performance musical no gig $g^{3}$ como antimúsica, em que o manuseio dos instrumentos náo consiste em tirar acordes, harmonias, ou seja, não são tocados de maneira convencional, e a voz consiste em gritos sem a intenção de conter melodias a não ser a própria entonação vocal. Percebo nos grupos que se enquadram na denominação musical 'punk rock', tanto nos seus países de origem quanto no Brasil, obras inteiras apresentadas desta maneira, outras em algumas partes soando como atimúsica e em outras, harmonias e melodias tanto instrumentais quanto vocais e ainda, há grupos que adotam o estilo definido como hardcore, caracterizado por eles como rápido e rasteiro, ou seja, uma música mais crua e superacelerada, em parte ou em toda a obra, da qual as bandas brasileiras se aproximariam.

\section{A Cena Brasileira}

De acordo com Ivone Gallo (2011), no Brasil, o punk surgiu por volta de 1977 na cidade de São Paulo e adjacências e logo depois se espalhou para o Rio de Janeiro, Brasília, Salvador, Recife, Rio Grande do Sul, Paraná. Pela primeira vez, jovens das classes trabalhadoras dariam o seu 'grito', retomando a crítica social e política por meio de uma 'música' que era entendida, a princípio, como 'rock'. Brasília era um polo de recepção e disseminação do punk rock para o Brasil; aquela música que tinha por lema o "do it yourself" (faça você mesmo) não exigia grandes aparatos e virtuosismo e qualquer garoto poderia fazê -la. Os primeiros grupos punks brasilienses surgiram quase concomitantemente aos grupos ingleses, como Plebe Rude, Detrito Federal e Aborto Elétrico. Em Salvador, Recife, Porto Alegre, Rio de Janeiro e São Paulo, conforme Gallo, o fenômeno punk também acontecia e incluo Belém nesta enumeração, visto que a primeira banda de punk rock surgiu em 1982. Então esse fenômeno estrangeiro era adotado e adaptado na América Latina:

Em cada contexto histórico e cultural do seu surgimento e trajetória o punk nunca se deu como imitação das matrizes originárias e procurou responder também a inquiriçôes e necessidades específicas. No Brasil as correntes mais críticas chocaram-se de frente com a ditadura o que lhes valeu perseguiçôes policiais e censura a interromper um fluxo natural de suas produçóes, além, é claro, da criminalização pela imprensa e pela mídia.(GALLO, 2010, p. 289)

Em 1978, em São Paulo, surgiram bandas como Restos de Nada, Ratos de Porão, Lixomania, Indigente, Anonimato, Cólera, Inocentes, onde o produto musical punk não se reduzia a uma mera imitação do estilo original e tinha um som de acento próprio, centrado na superaceleração e na curtíssima duração da (anti)música; as letras denunciavam a situação das classes trabalhadoras exploradas pelo sistema, falavam dos jovens oprimidos pelo desemprego, pela miséria e pela repressão policial. Na sua estilística, usavam bem mais

3 Gíria da língua inglesa que significa performance musical ao vivo. O termo foi adotado pelos punks com o sentido de não haver estrelas e nem a dicotomia: palco x público. 
o tom preto em relação aos punks ingleses e, diferente destes, os daqui não usavam cabelos coloridos apesar de os cortes serem semelhantes, salvo algumas exceçóes.

Em 1982, houve o festival O Começo do Fim do Mundo, gerando e propagando a cena punk rock paulista e brasileira. Em Belém, nesse mesmo ano, a banda Stress foi a primeira, no Brasil, a lançar um LP de heavy metal4 no estádio Leônidas Sodré de Castro e convidou para a abertura as bandas Chronos, Apocalipse e a banda The Podres, a qual seria considerada a primeira banda punk rock de Icoaraci, distrito de Belém, e talvez do Pará. Seu nome mudou depois para Insolência Públika.

\section{A Cena Local}

Certo grupo de jovens da capital paraense já acompanhava o movimento punk e, portanto, sua (anti)música. Entrevistei alguns desses grupos, os quais afirmaram que a adaptação do visual ao clima local resultou numa composição um pouco diferente do punk estrangeiro com jaquetas de couro e arrebites ${ }^{5}$ com algumas exceções. Usavam roupas mais leves, calças rasgadas e camisetas de algodão, por vezes pegavam camisas distribuídas por políticos na rua, viravam-nas do avesso e pintavam nomes de banda ou frases de protesto, mas ainda assim, o visual era agressivo e destoante com relação à sociedade local. Segue foto da banda Desgraça Periférica na periferia de Belém registrada em 1989. (Imagem 1)

Imagem 1: Banda Desgraça Periférica

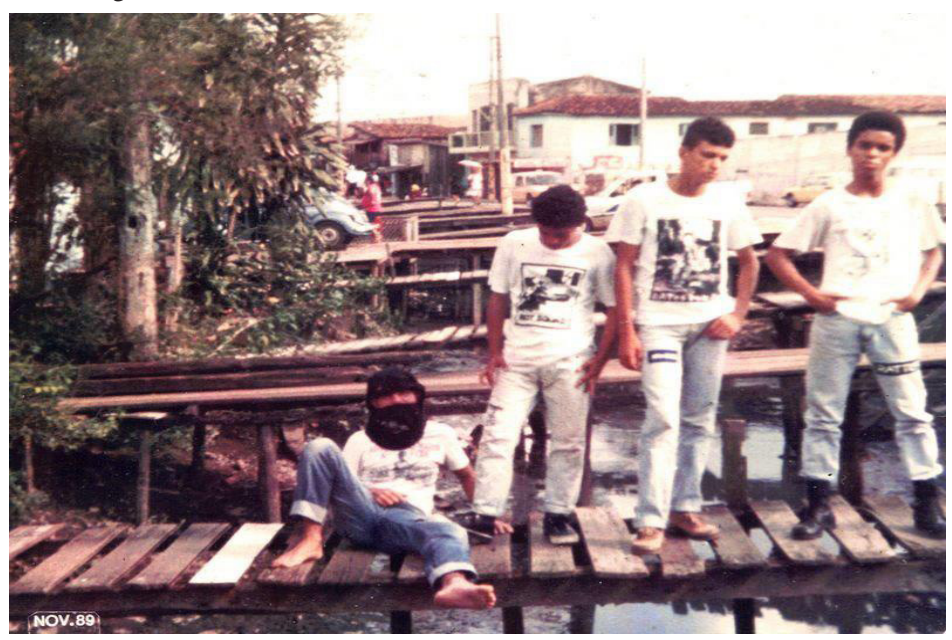

Fonte: Movimento punk

A periferia era não apenas um lugar frequentado por esses jovens, mas era onde a maioria residia, por vezes em situaçóes sociais e econômicas precárias, sem saneamento básico e passando fome, situação propícia às suas denúncias.

$4 \quad$ Gênero do rock que se desenvolveu no final da década de 1960 e no início da década de 1970, em grande parte no Reino Unido e nos Estados Unidos, tendo como raízes o blues-rock e o rock psicodélico, com um som massivo e encorpado.

5 Pequenas peças de metal, em forma de cone, geralmente cravadas em jaquetas, pulseiras e cintos. 
Seus pontos de encontro, denominados points eram, segundo Matheus, integrante da banda Contraste Social, onde,

vão chegando as informaçóes, vão trocando as ideias, vão se criando e se destruindo relacionamentos e vão se criando e destruindo bandas, zines ${ }^{6}$ novos e coletivos e é onde se cria toda a conspiração, é no point, aqui em alguns lugares do Brasil que a gente foi criando o point, foi lá que se foi criando protestos" (Matheus, entrevista, maio de 2018)

Os points eram principalmente praças e, curiosamente, a Praça Barão do Rio Branco, mais conhecida como Praça da Trindade, por ficar em frente à Paróquia da Santíssima Trindade é considerada um dos lugares principais da época por estes grupos que se identificavam como ateus, num contraste entre paisagens e ideologias. A respeito dos zines em Belém, seus textos verbais e não verbais possuíam conteúdos locais e globais, de bandas belenenses, nacionais e de outros países, conforme a Imagem 2.

Imagem 2: Zine Secreção Esporádica

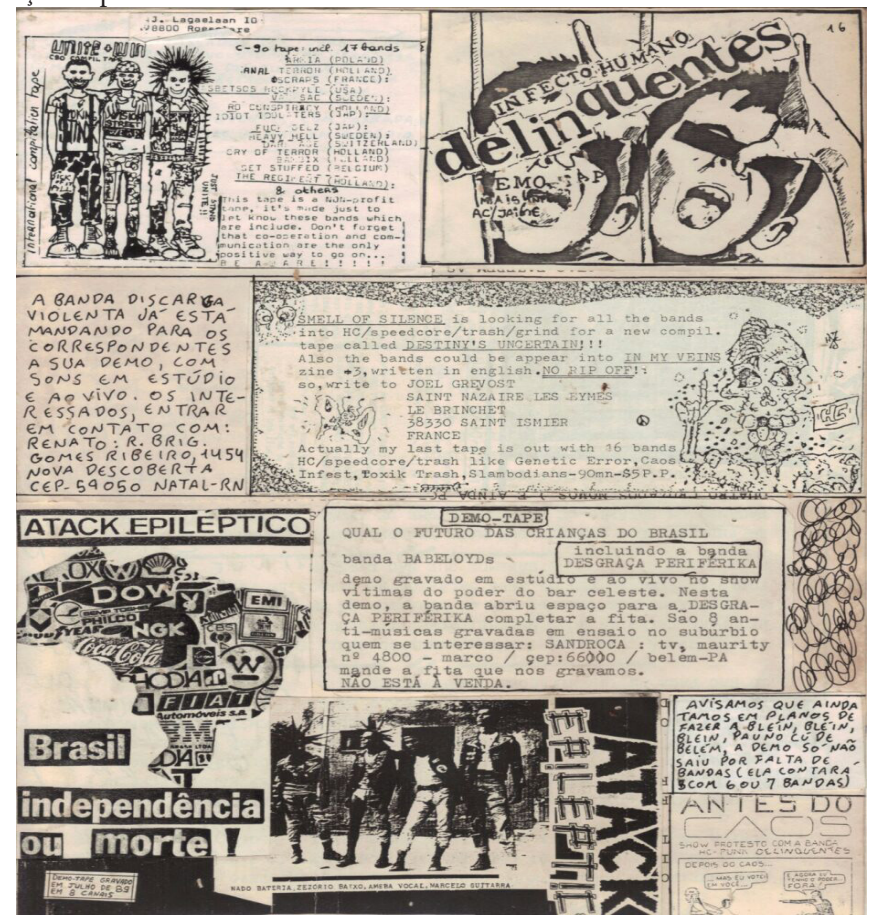

Fonte: Movimento punk

Numa análise de seu conteúdo, sua forma e sua linguagem, da esquerda para a direita, este zine é uma produção artesanal (como eram todos) em que parte é escrita à mão, parte na máquina de datilografia e xerocado para ser distribuído. Criado nos anos 90 traz informaçóes sobre: uma coletânea com bandas internacionais da Holanda, França, E.U.A. entre outros países; a banda local Delinquentes; uma banda de Natal - RN, visto que a comunicação com bandas do nordeste era constante; uma banda francesa; a

6 Termo que vem da língua inglesa: fanatic + magazine (revista de fā). 
banda mineira Atack Epiléptico, observando-se o termo Atack com um único ' $\mathrm{t}$ ', num misto entre português e inglês; uma demo da banda Baby Loyds (escrito BABELOYDs, com o ' $y$ ' substituído pelo grafema 'e', talvez pela semelhança entre as duas letras.)

Há, portanto, uma 'hibridaçáo' na obra e performances estudadas até aqui, no sentido de troca, mistura entre culturas diferentes, tal como a diversidade cultural relatada por Bhabha (1998) como intercâmbio de signos culturais, algo visível no processo de criação dessas bandas.

Retomando a questão (anti)musical, como já foi dito, a banda Insolência Públika, concebida pelos irmãos Beto e Regi, foi pioneira no (sub)gênero punk rock, mas sempre com acordes bem definidos, apesar de ter adotado o estilo hardcore por uma parcela de tempo. O vocalista Regi, em entrevista para esta pesquisa, afirmou que preferiu que o público entendesse o que se cantava e revelou, inclusive, que gostava de gêneros que não pertenciam à classificação rock, como a ciranda, por exemplo. A primeira composição da banda retratava o que viam ao seu redor no conjunto e no bairro onde viviam: vida simples, sem muita expectativa de melhoria na moradia, saneamento, no desenvolvimento dos indivíduos como cidadãos, sem poder aquisitivo para a educação e sucesso na vida profissional, dentre outras angústias. Então, gritaram sua própria realidade:

COHAB Zona Suja

COHAB, zona suja

COHAB, infecto-imunda

Quero respirar onde tudo é igual

Pessoas vazias

Pessoas vazias

Só servem pra fazer o fucking geral.

Apesar de cantada em português, observa-se a gíria em inglês como elemento da língua importada. Ficaram conhecidos por sua performance inusitada, ao abrirem para o show da banda Stress:

Peguei mamão, tomate, banana, essas coisas estragadas que tem na fruteira e o Beto fez um monte de ratinhos de palha de aço e eu levei lixo [...] coloquei perto da bateria e quando começou a tocar o Beto já pegou rato, jogando rato na galera, fazendo a maior onda...quando ía terminando a música eu peguei o saco de lixo, fui lá pra beira do palco, meti a máo e comecei a jogar na galera, estava lotado, pegava na cara da galera e não tinha nem como sair, desviar, saco de lixo pra tudo que foi lado, banana na cara da galera...quando a gente viu, começou a voltar tudo isso que nós tínhamos jogado, junto com grama. (Regi, entrevista, janeiro de 2016).

A atitude dos irmãos, muito jovens naquela época, ratifica a ideologia punk importada, como explica Matheus: "a sujeira sempre está presente no punk, seja a sujeira do próprio indivíduo como a sujeira também do sistema, do governo, da autoridade, das coisas que os punks vieram se levantar contra" (informação verbal) 7 . Tal postura - conservada, posteriormente, por bandas punks que foram surgindo na cidade - tornou a performance da banda hibridizada ao mesclar-se com o que se tinha acesso: o costume de se moldar ratos com palha de aço e de se ter frutas deterioradas pelo clima local nas fruteiras.

Em seguida vieram outras bandas, dentre elas, Anomalia, Contraste Social, Gestapo e Delinquentes, pelas periferias de Belém, também com a formação clássica do punk $7 \quad$ Entrevista concedida por Matheus em 22 de maio de 2018. 
rock - guitarra, baixo e bateria - e que anos depois, gravariam uma coletânea intitulada "Gritos de Agonia e Desespero" (1992) com letras gritadas na língua portuguesa, considerada um marco do movimento em Belém. Integrantes dessas bandas e de algumas outras se reuniam em centros culturais anarquistas para discutir políticas, modos de ação, entre outras questôes. Alguns estudavam esperanto, língua de resistência, oprimida pela igreja católica, para se comunicarem com punks que a adotavam em rede mundial. Havia locais de ensaio denominados com o nome "buraco periférico", onde alguns punks moravam num esquema de coletivismo.

Das bandas aqui enumeradas, Insolência Públika, Gestapo (cujo nome mudou para Ato Abusivo) e Delinquentes atuam até hoje na cidade, sendo que esta última mudou seu estilo musical para o chamado crossover $^{8}$ e foi objeto de pesquisa de Lucas Padilha de Sousa, músico que encerrou em 2016 o mestrado em Artes na UFPA, retratando a poética da banda com o objetivo de investigar sua importância na cena musical por meio de um filme etnográfico. Esse e outros poucos trabalhos, alguns ainda sendo desenvolvidos, como minha tese e a de outro colega sobre a cultura punk, refletem mesmo que timidamente, o interesse acadêmico por este objeto na cena local.

Bandas como: Desesperados, O Ceifador, Ovo Goro, Ácido Cítrico, O Orador e Delinquentes, nem todas punks, frequentavam um lugar de coletividade cultural chamado República dos Camaróes ${ }^{9}$ para reproduzir suas ideias e produtos culturais. Jayme, vocalista das bandas Desesperados e Delinquentes, revela como o espaço era importante para a cena: "digamos que o resultado disso tudo, a vitrine do que era a [Praça da] República, aconteceu em dois eventos ali perto, no Centro Comunitário Tucunduba, onde rolou o VariaSubs I e II, como uma resposta ao elitizado [evento] Variasons" (informação verbal) ${ }^{10}$; Jayme se refere a grupos de punks que frequentavam a Praça da República no Centro de Belém e que formavam bandas para tocar em eventos alternativos, movimentando portanto a cena local. A banda Baby Loyds surgiu neste espaço. Seu principal fundador, Gerson Costa, faleceu em 2015, mas deixou bem claro o papel do punk rock:

Fazemos punk rock [...] principalmente, por ideologia e atitude, com a finalidade de provocar a reflexão e o debate no público, principalmente nos mais jovens, sobre as contradições da política social e cultural existente em nossa sociedade. $\mathrm{O}$ nosso estilo, porém, não tem um grande público, não gera boas rendas, não se ganha dinheiro com isso. Fazer punk rock, então, é resistir à cultura massificada instituída pelas mídias. O punk rock tem para nós, portanto, um caráter educativo, pois tentamos levar os fấs a refletirem sobre suas vidas. Podemos dizer, então, que nosso estilo é de um trabalho que serve à educação política do público e da própria banda (COSTA, 2010).

As bandas da cena local citadas assimilaram elementos estrangeiros que são da própria origem do punk rock. Não apenas o ideal punk, como disse Gerson Costa em entrevista, mas a língua dos países de origem pode ser observada, inclusive, em alguns nomes de banda: The Podres, como uma fusão entre inglês e português, numa alusão ao sobrenome 'Rotten'(podre) do vocalista da banda Sex Pistols; Baby Loyds, como um estrangeirismo para fazer referência ao quão jovens eram seus integrantes.

8 Gênero mais propício a misturas, interseçôes de células rítmicas de outros gêneros musicais.

9 Camarão é um crustáceo típico da América Latina, muito consumido na Amazônia, fato curioso que prevê um diálogo da cultura local com a global das origens do punk.

10 Entrevista concedida por Jayme em 19 de março de 2017. 
De acordo com estas observaçóes, chamo a atenção para o fato de haver possíveis diálogos entre o global e elementos da região amazônica implícitos nestes grupos. O fazer artístico dessas bandas abrange, ainda, áreas do conhecimento como antropologia e sociologia, entre outras, visto que o punk, no Brasil e no Pará, de início não foi apenas um movimento musical, mas cultural e até político por agregar muitos anarquistas como músicos ou público desse (sub)gênero, e ainda, os integrantes dessa cena, nos anos 80 , recebiam correspondências, pelo correio, de outros punks do Brasil, tinham acesso a fitas k-7, LPs, fotos, à música de bandas punks suecas, inglesas e finlandesas nas poucas lojas de selos independentes que trabalhavam com a venda deste material, quando não, pediam pelo correio; ou seja, uma situação favorável à troca entre elementos sonoros "locais", "globais" e até posturas e estéticas de bandas estrangeiras.

\section{Gritos de Agonia e Desespero}

Márcia da Costa (2006), ao citar as 'culturas juvenis' definidas por Feixa (1999), incluindo-se os punks, afirma que ao adotarem certos estilos de vida, são negativamente denominadas pela sociedade ou assumem um estereótipo negativo autodenominandose como gangue. Inclusive, ao se manifestarem no Brasil, expressariam um processo que é fruto da globalização, com tensôes globais que produzem localidades e novas modalidades globalizadas. Porém, a partir da década de 80 , pesquisadores dessas culturas preocuparamse com a não estigmatização de uma parte desses jovens negando a denominação 'gangue', a qual cabia para delinquentes ou bandidos, sendo a maioria dos jovens provenientes das camadas subalternas da populaçáo. Por conta desse estigma, a banda Delinquentes tomou para si o estereótipo evitado iniciando suas atividades musicais no início dos anos 90. Esta, Anomalia, Contraste Social e Gestapo gravaram a coletânea Gritos de Agonia e Desespero, em fita cassete, com 31 faixas divididas entre as bandas, em 1992, no estúdio Skala que funcionava no subsolo da casa de show Kalamazoo, no bairro do Una. Seguem as fotos 3, do encarte totalmente artesanal, lembrando os zines, e 4, a fita em si.

Imagem 3: Encarte da fita cassete
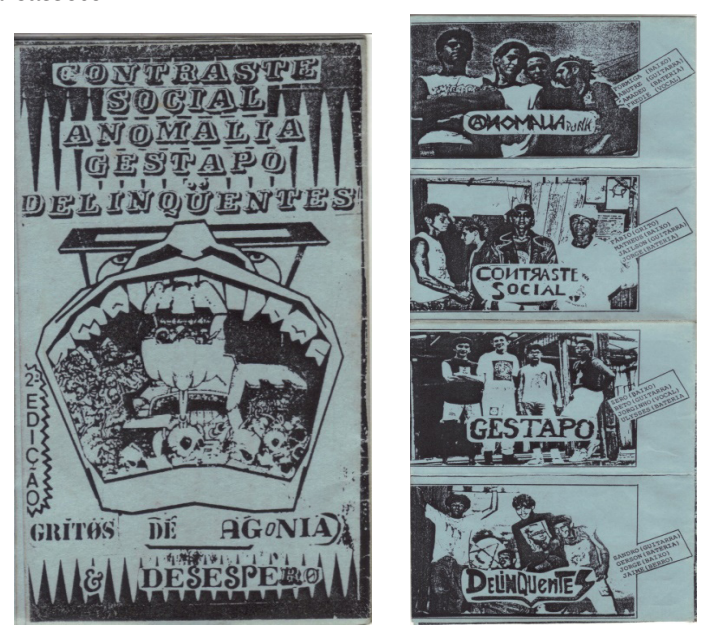

Fonte: Movimento punk 
Imagem 4: Fita cassete frente e verso.
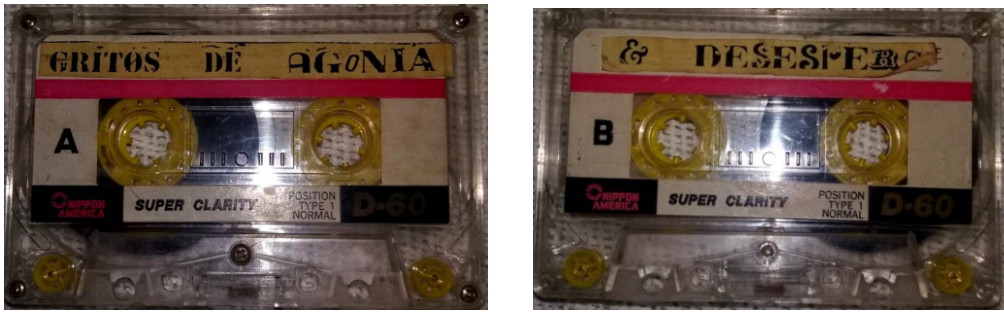

Fonte: Arquivo pessoal de um fă ${ }^{11}$

As obras destas quatro bandas chegaram a influenciar o movimento nas regiôes norte/ nordeste brasileiras. Os elementos originais do punk rock foram mantidos, inclusive por todas as bandas da coletânea, como: música de curta duração, guitarra com distorção, o vocal gutural letras críticas em português, ao retratarem o cotidiano dos trabalhadores assalariados, aposentados ou excluídos, do povo brasileiro que sofria exploração de alguma forma, além de denunciarem o sistema governamental e a repressão policial em termos locais e globais. A intenção principal era conscientizar o seu público para que todos juntos fizessem algo, buscassem soluçóes. As bandas conseguiram veicular seu conteúdo na Rádio Cultura local.

Curiosamente a banda Gestapo adotou o nome da polícia secreta alemã 'Gestapo', pois justamente por ser o punk antifascista, a banda o adotou com ironia, porém, mudou depois para Ato Abusivo. Segue o exemplo de uma letra desta banda, com uma temática que retrata uma realidade constante no Pará:

Sul do Pará - Gestapo

Fazendeiro mandou matar o líder dos Sem Terra

Estrangeiro expulsou seringueiro do seu lugar

Garimpeiro invade terra de índio só pra explorar o chão

Sul do Pará, morte e perseguição.

Gravada em 1990, começa com o baixo, em compasso binário, fazendo o fraseado (D C\#m A Bm C\#m) duas vezes, em seguida entra a guitarra, com distorção, executando a frase por quatro vezes; ao entrar o vocal, após 31 segundos, gritando a letra de maneira falada, há uma superaceleração de todos os instrumentos, a partir daí não há mais definição de acordes e a banda passa a executar a antimúsica. Em cada verso, a voz acentua apenas uma sílaba da primeira palavra e uma da palavra final, como querendo acompanhar o compasso binário. Após os versos, soa um pouco da nota final da guitarra e entra um trecho instrumental de Carimbó, ritmo típico da regiāo paraense, já com a guitarra sem distorção. A música tem 1 minuto e 7 segundos, visto que uma das características do punk rock é sua curta duração.

A banda inclui uma temática que retrata uma realidade constante na Amazônia e principalmente no Pará: o conflito de terras; e além de retratar a realidade local, incluiu um trecho de Carimbó, gênero musical típico da regiáo, o qual quebra totalmente os padróes de uma composição punk. Sobre a inserção de um ritmo local na canção da banda, o autor Beto afirma: "Tão punk como é uma banda de punk rock hc [hardcore] é o movimento que essa galera da cultura popular faz também de estar resistindo ali; então eu vejo assim: é resistência, pra mim é punk, merece o meu respeito!" (informação verbal) ${ }^{12}$.

11 O fă preferiu não ser identificado.

12 Entrevista concedida por Beto em 27 de maio de 2018

ICTUS Music Journal vol. 14 n.1 
É importante ressaltar que a cançâo foi bem aceita por parte do movimento punk de Belém e de outras cidades brasileiras, principalmente do Nordeste, com quem as bandas daqui se relacionavam culturalmente, socialmente e politicamente com a troca de cartas registradas pelos correios, visto que o gênero Carimbó, também vindo da periferia, do interior do Pará, antes de se tornar patrimônio imaterial, era considerado marginal e chegou a ser proibido na cidade junto com qualquer tipo de batuque. Então, a inserção de elementos locais de resistência seria bem vinda à adaptação do punk rock no Brasil, num diálogo intercultural.

Na coletânea existe, ainda, outra canção com a mesma temática, chamada Assassinato de um Líder Rural, pois segundo os integrantes da banda, ocorreram muitos crimes por conta da posse de terras na época em que essas cançóes foram criadas. Segundo eles, essa canção chegou a ser executada num acampamento dos sem terra, em Belém, em frente à sede do INCRA. O Movimento dos Trabalhadores Rurais Sem Terra (MST) é um movimento social camponês que surgiu em 1984, no Brasil, ou seja, uma causa nacional; portanto, a ligação da banda com elementos nacionais e locais, tendo como exemplo os conflitos agrários no Pará, dialoga com elementos globais na música e na estética desta banda de punk rock.

A respeito dessa musicalidade híbrida notória nas composiçóes das bandas, principalmente da Gestapo, cito Stuart Hall (2006) que se refere à 'pluralização' de identidades: "As transformaçôes associadas à modernidade libertaram o indivíduo de seus apoios estáveis nas tradiçóes e nas estruturas" (p. 25). Por considerar a música, mais especificamente a cantada, uma linguagem por onde transitam várias identidades provenientes de vários aspectos culturais de tempo e espaço diferentes, dialogo também com Néstor García Canclini (2008) que questiona modernização e modernidade na América Latina, junto ao termo 'hibridaçáa', no sentido de mestiçagem, sincretismo, fusão e outros vocábulos empregados para designar misturas particulares. A hibridação como troca, mistura entre culturas diferentes é visível no processo de criação dessas bandas em Belém desde sua estreia até os dias atuais.

A presença da língua mãe, as temáticas apresentadas da realidade local e a liberdade para a inserção de elementos musicais regionais complementam o que vem a ser o punk rock na Amazônia: uma mistura de culturas sem que o gênero musical absorvido perca a sua essência.

\section{Conclusão}

O rock hoje é um gênero musical que se fundiu a uma série de outras informaçóes, sendo que o punk rock manteve seu teor crítico. A trajetória e o campo das composiçóes das bandas estudadas revelam que as mesmas, inseridas no contexto latino-americano, absorvem várias identidades e um caráter híbrido que se mostra presente no Brasil e, em especial, na região amazônica. Há diálogo entre os saberes da região e de localidades externas, inclusive dos países que geraram esse estilo musical, que permeiam as canções, a cultura das bandas punks em Belém. Suas interfaces epistêmicas são um incentivo à pesquisa de música urbana na região, sendo que cada gênero ou subgênero musical guarda suas particularidades da regiáo e de outras localidades.

No produto dessas bandas podemos enxergar ora a música, visto que há instrumentos convencionais, como contrabaixo, guitarra elétrica e bateria que extraem acordes, ritmo e melodias, numa organizaçáo pensada de forma musical, ora o que as bandas denominam 
antimúsica, numa desorganização de sons que começam e terminam de modo anticonvencional, em que a obra não é tocada necessariamente do mesmo jeito, mas cumprindo, sendo que o título de cada obra e a letra são os mesmos.

A (anti)música dessas bandas deve ser analisada, portanto, como um processo de criação musical que considera fatores sociais, econômicos e culturais, de modo a detectarmos elementos externos ou internos à sua localidade. Essas composiçóes, pensadas de forma individual e coletiva, são um reflexo da sociedade em que vivem e da sua própria cultura desde a chegada do punk rock em Belém até os dias de hoje, havendo evolução das temáticas de acordo com os problemas que vão surgindo na Amazônia e em outras partes do mundo, visto que a denúncia pode ser focada num espaço macro ou micro, independente de os grupos se situarem em localidades urbanas.

A tecnologia, inclusive, tem contribuído muito para o acúmulo de informações de diversas fontes e as bandas de Belém que atuam com a crítica social, tratam de problemas e contradiçôes sociais e políticas locais e globais e querem devolver o seu produto para o mundo seja como uma nova crítica e/ou uma nova mistura rítmica e/ou estilística.

Sobre o aspecto puramente musical, hoje o rock em Belém que mais se aproxima do gênero punk é considerado hardcore, adotando-se a abreviatura 'hc' - expressão que significa algo executado de forma dura e extrema - numa cena que se denomina punk/hc, variando, por vezes, o subgênero que dizem executar, com nomes como fastcore, emocore, thrashcore, entre outros. Dificilmente uma banda que surgida nos anos 2000, em Belém, autodenomina-se punk. Restam algumas poucas das antigas e muitas vezes tocam em eventos separados das bandas dos jovens. Talvez os anos 1980 e 1990 sejam constituídos com momentos únicos de militância fervorosa aliada à (anti) música e de uma boa quantidade de bandas de punks em Belém. 


\section{Referências}

ABRAMO, Helena Wendel. Cenas Juvenis, punks e darks no espetáculo urbano. São Paulo: Scritta, ANPOCS, 1994.

BÉHAGUE, Gerard. Fundamento sócio-cultural da criação musical. Revista ART 019, p. 5-17, Agosto 1992.

Beto. Entrevista de Keila Monteiro em 27 mai. 2018. Belém. Gravação.

BHABHA, Homi K. O local da cultura. Trad. Myriam Ávila, Eliana Lourenço de Lima Reis, Gláucia Renate Gonçalves. Belo Horizonte: Ed. UFMG, 1998.

BLACKING, John. How musical is man? Seattle: University of Washington Press, 1990.

CAIAFA, Janice. Movimento punk na cidade: a invasão dos bandos sub. Rio de Janeiro: Jorge Zahar, 1985.

COSTA, Gerson. A rebeldia do punk rock na metrópole da Amazônia. Jornal Inverta. Belém. Edição 443, 2010. Disponível em: <http://inverta.org/jornal/edicao-impressa/443/ entrevista>. Acesso em 10 jan.2017>.

COSTA, M. R.; SILVA, E. M. (Org.). Sociabilidade juvenil e cultura urbana. São Paulo: Educ, 2006.

FÉRAL, Josette. Por uma poética da performatividade: o teatro performativo. Sala Preta. São Paulo, v.8, p. 197-210, abr. 2009.

GALLO, Ivone. Por uma Historiografia do Punk. Projeto História: Revista do Programa de Estudos Pós-Graduados de História, [S.l.], v. 41, ago. 2010. ISSN 2176-2767. Disponível em: <https://revistas.pucsp.br/index.php/revph/article/view/6542>. Acesso em: 02 mar. 2018.

GARCÍA CANCLINI, Néstor. Culturas híbridas: estratégias para entrar e sair da modernidade. 4. ed. Trad. Heloísa Pezza Cintrão; Ana Regina Lessa. São Paulo: Editora da Universidade de São Paulo, 2008.

GRITOS DE AGONIA E DESESPERO. Belém, 1992.1 cassete sonoro (36 min), mono.

HALL, Stuart. A identidade cultural na pós-modernidade. Trad. Tomaz Tadeu da Silva e Guacira Lopes Louro. 11 a ed. Rio de Janeiro: DP\&A, 2006.

Jayme. Entrevista de Keila Monteiro em 19 mar. 2017. Belém. Gravação.

MAGNANI, J. G. C.; SOUZA, B. M. (Org.) Jovens na metrópole: etnografias de circuitos de lazer, encontro e sociabilidade. São Paulo: Editora Terceiro Nome, 2007.

MERRIAM, Alan. The antropology of music. Evanston: Northwestern University Press, 1964.

Regi. Entrevista de Keila Monteiro em 15 jan. 2016. Belém. Gravação. 
SANTOS, Gabriel Barbosa. Expirados e inspirados. A influência da cena do rock psicodélico inglês e norteamericano na contracultura nacional (1967-1971). Rio de Janeiro: PUC, 2013.

SOUSA, Lucas Padilha de. Eu amo tudo o que náo presta. Punk e poética em trinta anos de Delinquentes. 2016, 60f. Dissertação de mestrado. PPGARTES/UFPA, 2016.

Matheus. Entrevista de Keila Monteiro em 22 mai. 2018. Belém. Gravação.

VELHO, Gilberto. Antropologia urbana: interdisciplinaridade e fronteiras do conhecimento. MANA 17(1), p. 161-185, 2011. Disponível em: <http://www.scielo.br/scielo. php?pid=S0104-93132011000100007\&script=sci abstract\&tlng=pt $>$. Acesso em 20 mai. 2019. 